\title{
Article \\ Theoretical and Experimental Research on Temperature Rise Mechanism of Oil in the Sealed Cavity of Intra-Vane Type Pump
}

\author{
Shaonian Li *(D), Pan Yang, Ru Zhao, Tao Liang and Zhiyuan Zhou
}

check for updates

Citation: Li, S.; Yang, P.; Zhao, R.; Liang, T.; Zhou, Z. Theoretical and Experimental Research on

Temperature Rise Mechanism of Oil in the Sealed Cavity of Intra-Vane Type Pump. Processes 2022, 10, 446. https://doi.org/10.3390/pr10030446

Academic Editor: Andrew S. Paluch

Received: 13 January 2022

Accepted: 15 February 2022

Published: 23 February 2022

Publisher's Note: MDPI stays neutral with regard to jurisdictional claims in published maps and institutional affiliations.

Copyright: (C) 2022 by the authors. Licensee MDPI, Basel, Switzerland. This article is an open access article distributed under the terms and conditions of the Creative Commons Attribution (CC BY) license (https:// creativecommons.org/licenses/by/ $4.0 /)$.
College of Energy and Power Engineering, Lanzhou University of Technology, Lanzhou 730050, China; yp_xzcz@163.com (P.Y.); lzlg2022@163.com (R.Z.); 18093172647@163.com (T.L.); anbian12581@163.com (Z.Z.) * Correspondence: lisn@lut.edu.cn; Tel.: +86-138-9319-7060

\begin{abstract}
To improve the performance of the intra-vane type pump and optimize the friction characteristics of the three friction pairs related to the vane cavity, theoretical analysis, numerical simulation, and experimental testing are used to study the mechanism of oil temperature rise in the sealed cavity of the vane pump. First, the heat generation source and heat dissipation routeways of the oil in the oil suction and oil discharge regions are analyzed, respectively. Thermodynamic modeling is conducted based on the principle of heat transfer. Then, the oil temperature rise caused by each heat generation source was simulated using the thermodynamic model. The influence of each heat generation source and heat generation route on the oil temperature rise change was analyzed and compared. Finally, a test system for oil temperature rise is designed, and the temperature changes at six positions of the experimental pump when working at three pressures are measured through experiments. Based on simulation and experimental results, the mechanism of oil temperature rise in the sealed cavity of the intra-vane type pump is analyzed and discussed. The experimental results show that the established thermodynamic model is very anastomotic to the experimental results. The experimental test value of temperature rise is greater than the calculated value. When the outlet pressure is $6 \mathrm{MPa}$, the maximum temperature rise of the theoretical calculation is $2{ }^{\circ} \mathrm{C}$. Meanwhile, the maximum temperature rise of the experimental analysis is $3.5^{\circ} \mathrm{C}$. The maximum difference of temperature rise between theoretical calculation and experimental test is $1.5^{\circ} \mathrm{C}$. Therefore, the model can effectively predict the oil temperature rise in the sealed cavity of the intra-vane type pump and provide theoretical guidance for the design of similar pumps.
\end{abstract}

Keywords: vane pump; sealed cavity; temperature rise; heat source; heat emission route

\section{Introduction}

The friction between the tip of the vane and the inner ring of the stator, the friction between the vane and the rotor slot, and the friction between the valve plate, rotor, and stator are the three pairs of frictions of the vane pump. The parts that make up the friction pair usually work under high-speed and high-pressure friction conditions, and their friction and wear conditions directly affect the service life, volumetric efficiency, and working pressure of the vane pump [1,2]. The sealed cavity consists of two adjacent vanes of the vane pump that passes through the oil suction and discharge regions. Under the action of the stator curve, the oil suction and discharge processes can be realized by changing their volume. The oil in the sealed cavity cannot complete the circulation well in each oil suction and discharge cycle. Additionally, it will absorb much of the heat generated by the friction pair. This part of the heat cannot be dissipated instantaneously, resulting in excessive oil temperature. Excessive oil temperature will decrease the viscosity of the oil. It can also cause the working environment of the parts in the pump to become harsh. The gap between the friction pairs will be changed, resulting in severe wear between the friction interfaces; thus, reducing the reliability of the pump, and making the pump unable 
to work normally [3]. Therefore, it is particularly important to study the mechanism of oil temperature rise in the sealed cavity of the vane pump.

The existing research results on the temperature rise of the friction pair of hydraulic pumps are mainly reflected in the axial piston pump. Wang Ruijie derived the calculation formula for the temperature rise of the oil in the slipper pair of the axial piston motor by combining the differential pressure and shear flows. They obtained that reducing the outer diameter of the oil cavity at the bottom of the slipper or increasing the inner diameter can reduce the temperature rise of the friction pair [4]. Wang Haiying optimized the cylinder size of the swash plate type axial piston motor and established a dynamic model to obtain the leakage and temperature rise of the piston pair [5]. Ma Jun established an instantaneous thickness field, pressure field, temperature field model, and friction and leakage model of the piston pair oil film. They numerically solved the dynamic temperature field of the piston pair [6]. Gao Dianrong constructed a liquid-solid mathematical model of heat transfer of an axial piston hydraulic motor pump, and analyzed the influence of ambient temperature on the motor pump's temperature rise. It was founded the average temperature rise of the motor pump increases linearly with the increase of ambient temperature [7]. Zhou Yang developed a "circular arc-involute-circular arc" circular arc gear pump. And the temperature rise of journal bearings in the pump was evaluated for bearings with and without herringbone grooves. The results revealed using herringbone groove on the inner wall of bearing was effective in reducing the temperature increase [8].

The research on the thermodynamics of hydraulic pumps has been concentrated on the axial piston pump by establishing simulation models and experimental designs.

Li Chenggong established a thermodynamic model of the piston pump using the law of energy conservation. They conducted a heat transfer analysis on the internal structure of the piston pump [9]. Han Menghu established a thermodynamic model of the piston pump based on the working process and heat transfer mechanism of the piston pump. They developed a simulation model for temperature simulation analysis of the piston pump [10]. Tang Zhenyu analyzed the heat generation and heat transfer of the water pressure piston pump using the principles of dynamics and heat transfer. They found that the largest heat source of the piston pump is the piston pair, and the principal routeway of heat dissipation is heat conduction [11]. Tang Hesheng proposed a heat balance gap formula based on the heat transfer relationship between the slipper pair and oil film. They discussed the influence of the inlet oil temperature on the heat balance gap under different working conditions and materials [12]. Sun Huguo established a thermodynamic model considering leakage and pressurization and a dynamic model considering mechanical loss for aviation piston pumps. Comparative analysis of the experimental and simulation results shows that the model can realize the study of the heat generation mechanism of the fuel piston pump [13]. Ivantysynova $\mathrm{M}$ conducted a systematic analysis of the heat transfer in the cylinder of the piston pump. They used finite element software to analyze the surface temperature distribution on the valve plate surface. The experimental test results show that the simulation results are consistent with the experimental results [14]. Li Donglin established the integrated thermodynamic model of water lubricating axial piston pump and analyzed the temperature rise characteristics and heat dissipation characteristics of the pump. It was found the difference of the steady-state temperature of water lubricating axial piston pump between simulation and experiment is less than $4{ }^{\circ} \mathrm{C}$, and its temperature distribution is uniform [15].

However, there are few studies on the temperature rise of the friction pair of the vane pump. In previous works, the author and his collaborators have developed theoretical derivation and numerical simulation on the temperature rise of the valve port of the highpressure vane pump. They obtained the temperature rise of different parts on the surface of the valve plate through experimental tests [16]. For research on the mechanism of oil temperature rise in the sealed cavity of the vane pump, no relevant research results have been found. In this paper, the model of heat generation and dissipation is established based on the analysis of the heat transfer route of the oil in the sealed cavity. Additionally, the 
value of the heat generation and dissipation of the oil in the sealed cavity of the vane pump is obtained using theoretical calculation and experimental testing methods. The research conclusions have certain reference significance for developing the high-pressure direction of the vane pump and improving its performance.

\section{Research Object and Methods}

The research object of this paper is a double-acting intra-vane type pump whose product model is 25VQ21A. Figure 1 shows the main components of the pump core. The rotor rotates under the drive of the motor. The vanes inserted in the rotor vanes slot rotate with the rotor while making telescopic movements in the radial direction [17]. The space between two adjacent vanes, the outer circular surface of the rotor, the inner curved surface of the stator, and the valve plate on both sides is a sealed cavity [18]. Each time the rotor of the double-acting intra-vane type pump rotates one round, the working cavity formed by two adjacent vanes completes the suction and discharge of oil twice.

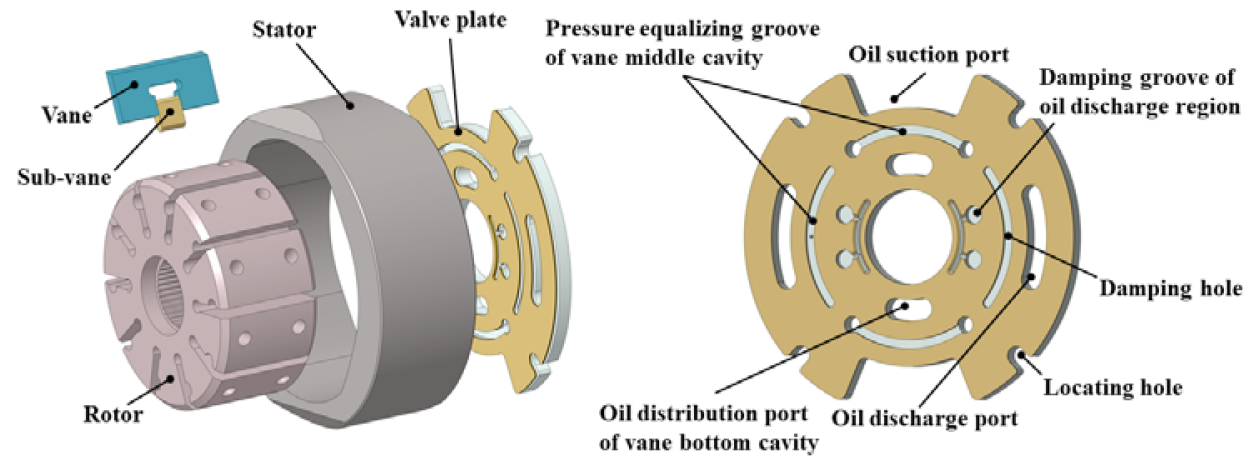

Figure 1. Diagram of the main components and valve plate.

For the oil in a sealed cavity as a thermodynamic system, it is known from the first law of thermodynamics that in a thermodynamic system, energy can only change from one form to another [19]. The change in internal energy in the thermodynamic system depends on the exchange of energy. Since there is no work process between the system and the outside ambient, the energy change expression of the system is given by

$$
\Delta Q=Q_{\text {out }}-Q_{\text {in }}
$$

where $\Delta Q$ is the increment of the internal energy, $\Delta Q_{\text {out }}$ is the energy leaving the system, and $\Delta Q_{i n}$ is the energy entering the system.

Figure 2 shows that the heat transfer route diagram in the sealed cavity of the intravane type pump can be obtained according to the structure and working principle of the vane pump.

The heat generation source transfers heat to the oil in the sealed cavity by convective heat transfer, and the oil transfers heat to the inner wall of the stator, the inner wall of the pump shell and other related parts in the pump through convective heat transfer. The conduction resistance of the stator is smaller than the convection resistance of its surface. Therefore, the temperature between the inner and outer walls of the stator can be regarded as the same, and the heat conduction between the inner and outer walls of the stator can be ignored. Heat is transferred between the inner and outer walls of the shell through heat conduction. The high-temperature inner surface transfers heat to the low-temperature outer surface. In contrast, the outer wall of the shell transfers heat to the ambient through radiative heat transfer and convective heat transfer. As shown in the figure, the temperature change of the oil in the sealed cavity is related to the movement of the various parts inside the vane pump. Therefore, to establish the overall thermodynamic model of the sealed cavity, the thermodynamic models of each heat source and heat dissipation route in the sealed cavity must be established separately. 


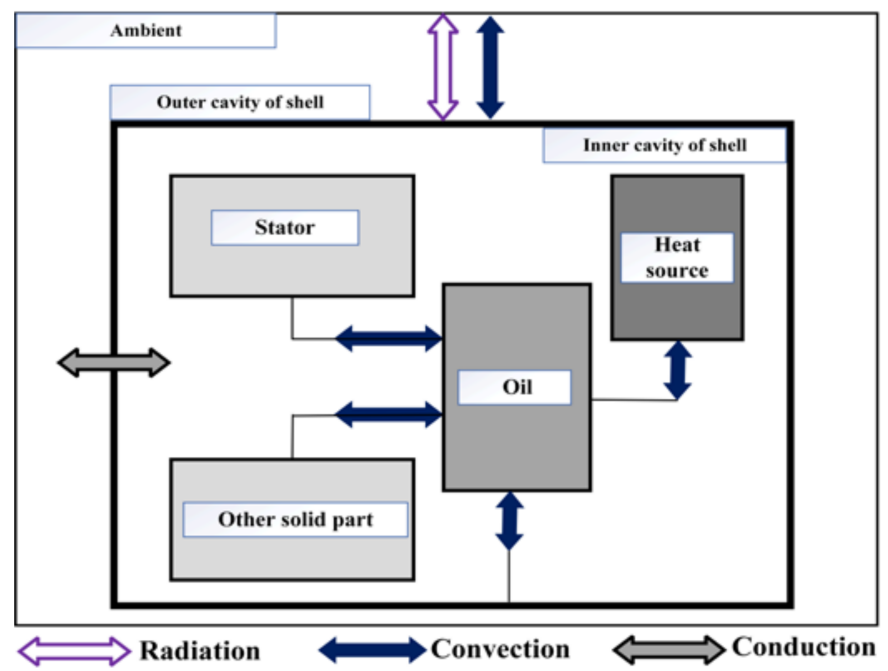

Figure 2. Schematic of oil heat transfer in the sealed cavity.

\section{Establishment of Thermodynamic Model}

The heat generation in the pump mainly includes leakage and friction heat. Since the valve plate of the vane pump adopts a special structure that can float axially according to the pressure, the leakage of the vane pump during high-pressure operation is reduced. Thus, the leakage heat generation inside the vane pump can be ignored. This paper only considers the frictional heat generation of the vane pump, which includes frictional heat generation between the vane and the inner surface of the stator ring, the friction between the vane and rotor slot, and frictional heat generation between the vane, rotor, and valve plate. The frictional heat generated between the vanes and the valve plate is absorbed by the valve oil film. Therefore, heat generation can be converted into an analysis of the contribution of the oil film temperature rise to the oil temperature of the sealed cavity.

\subsection{Heat Generation of Oil in Oil Suction Region}

The oil temperature rise in the sealed cavity of the oil suction region is mainly caused by friction between the vane and the inner surface of the stator ring, friction between the vane and rotor groove, and the corresponding valve plate oil film on both sides of the sealed cavity of the oil suction region.

\subsubsection{The Frictional Heat Generation of the Vane}

When the vane pump is working, the vanes reciprocate radially along the rotor slot, and the vane and the rotor slot are always in a state of friction and heat generation. Simultaneously, the vanes rotate with the rotor, and the friction heat generation state between the vanes and the inner surface of the stator ring has been maintained. Therefore, it is necessary to analyze the force of the vanes in the suction region [20,21].

Figure 3 shows that the force balance equations are established along the radial and vertical directions of the vane, and the sum of the moments of each force to point $\mathrm{A}$ is zero [22].

$$
\begin{gathered}
N_{\mathrm{x} 1} \cos \gamma+N_{\mathrm{x} 3} f \sin \gamma+F_{a}-F_{r}+N_{\mathrm{x} 1} f+N_{\mathrm{x} 2} f-F_{p}=0 \\
N_{\mathrm{x} 2}-N_{\mathrm{x} 1}-N_{\mathrm{x} 3} f \cos \gamma+N_{\mathrm{x} 3} \sin \gamma-F_{k}=0 \\
N_{\mathrm{x} 2} h-N_{\mathrm{x} 1} A C-F_{k} d-F_{r} \frac{s}{2}+F_{a} \frac{s}{2}+N_{\mathrm{x} 2} f s-F_{P} \frac{s}{2}=0
\end{gathered}
$$

where, $N_{x 1}$ and $N_{x 2}$ is the contact reaction force of the rotor groove on the vane; $N_{x 3}$ is the contact force of the stator ring on the tip of the vane; $\gamma$ is the pressure angle of the vane on the transition curve; $F_{r}$ is the centrifugal inertia force acting on the center of mass of the vane as shown in point $\mathrm{B} ; F_{a}$ is the acceleration and deceleration sliding inertia force acting on the vane; $F_{k}$ is the Coriolis inertial force; $F_{p}$ is the hydraulic force acting on the bottom 
of the vane caused by oil pressure; $h$ is the height of the vane along the radius; $A C$ is the length of the vane protruding outside the rotor slot; $d$ is the length from the center of mass of the vane to the tip of the vane; $s$ is the thickness of the main vane; $f$ is the coefficient of friction.

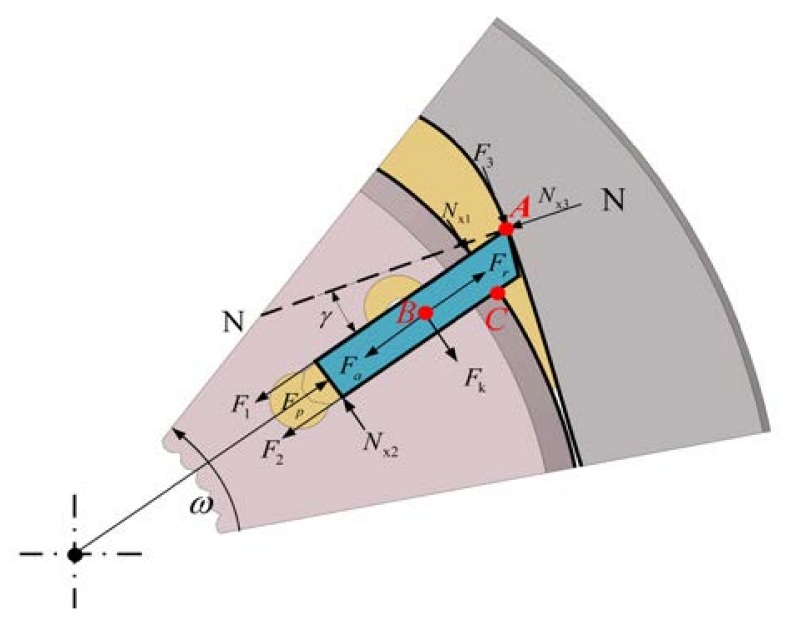

Figure 3. Force analysis of vanes in the oil suction region.

Due to the short movement period of the vane, heat generation analysis can be conducted according to its movement. According to the structure of the vane pump, the integration interval calculates the time it takes for the previous vane of the vane sealed cavity to turn through the suction region as $3 \pi / 10 \omega$, where the $\omega$ is the rotational angular velocity of rotor. The frictional heat generation equation between the vane and the inner surface of the stator ring and the frictional heat generation equation between the vane and the rotor slot can be obtained as follows:

$$
\begin{gathered}
Q_{1}=\int_{0}^{\frac{3 \pi}{10 \omega}} z N_{x 3} f \omega \rho d t \\
Q_{2}=\int_{0}^{\frac{3 \pi}{10 \omega}} z\left(N_{x 1}+N_{x 2}\right) f v d t
\end{gathered}
$$

Where, $Q_{1}$ is the friction heat generation between the vane and the inner surface of the stator ring; $Q_{2}$ is the friction heat generation between vanes and rotor grooves; $z$ is the number of vanes of the vane pump; $\rho$ is vector diameter of vane motion; $v$ is the radial velocity of vane in blade groove of the rotor.

\subsubsection{The Temperature Rise Caused by the Oil Film in the Oil Suction Region}

When the pump rotates, the shaft drives the rotor and vanes in the rotor slot to rotate. The oil film formed between the valve plate and the rotor and the vane is not static but constantly flowing. The influence of the oil film in the suction region on the oil temperature of the sealed cavity is analyzed as follows.

Figure 4 shows that the upper part of the region is connected to the oil suction region of the pump at the oil suction region A, and this region has low-pressure oil [23]. The lower half of the region is connected to the oil cavity formed by the sub-vanes and the rotor groove, and this region has high-pressure oil [24].

Therefore, the pressure difference between the upper and lower regions will cause the oil film in the region A to flow radially outward. For the oil film of the entire valve plate pair, the relative rotation between the valve plate and the rotor and the vanes makes the oil film perform shear flow. Therefore, the movement mode of the oil is the pressure difference flow and shear flow, which are orthogonal. 


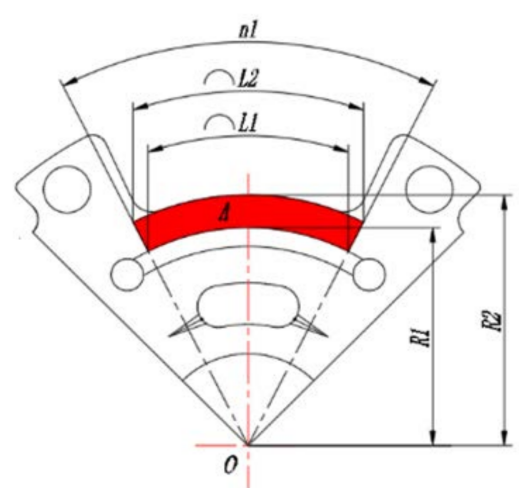

Figure 4. Schematic of mathematical model for region A.

For region $\mathrm{A}$, the average arc length $\mathrm{L}$ is given as follows:

$$
L=\frac{L_{1}+L_{2}}{2}=\frac{3 n_{1} \pi\left(R_{1}+R_{2}\right)}{20}
$$

where $n_{1}$ is the angle corresponding to the region $\mathrm{A}$ of the oil suction region on the valve plate. Then, the average relative sliding speed $U$ is given by

$$
U=\frac{\pi n\left(R_{1}+R_{2}\right)}{60}
$$

Where $n$ is rotating speed of the rotor.

Then, the composite flow can be obtained from the vector sum of the differential pressure and shear flows given by

$$
q=\sqrt{\left(\frac{\Delta p L h^{\prime 3}}{12 \mu b^{\prime}}\right)^{2}+\left(\frac{b^{\prime} h^{\prime} U}{2}\right)^{2}}
$$

Since the two flow directions are orthogonal, the friction loss power $E_{f}$ only depends on the friction resistance generated by the shear stress given by

$$
E_{f}=\frac{\mu b^{\prime} L^{\prime} U^{2}}{h^{\prime}}
$$

where $\mu$ is the oil viscosity; $h^{\prime}$ is the thickness of the oil film of the valve plate pair; $b^{\prime}$ is the width of the region A.

Suppose the heat increase in the oil in the sealed cavity caused by the valve pairs on both sides is $Q_{3}$. According to the law of energy conservation, the thermal power of one side $P_{1}$ is calculated as follows:

$$
P_{1}=\Delta p q+E_{f}=\rho_{1} c_{1} q \Delta T
$$

where $\rho_{1}$ is the density of oil; $c_{1}$ is the specific heat capacity of oil;

Combining equations (7) to (11), the temperature rise can be obtained as follows:

$$
\Delta T=\frac{\Delta p}{\rho_{1} c_{1}}+\frac{\mu^{2} b^{\prime 2} \pi^{2} n_{1} n^{2}\left(R_{1}+R_{2}\right)^{2}}{100 h^{\prime} \rho_{1} c_{1} \sqrt{9 \Delta p^{2} h^{\prime 6} n_{1}^{2}+4 \mu^{4} b^{\prime 4}}}
$$

\subsection{Heat Generation of Oil in the Oil Discharge Region}

According to the movement mechanism of the sealed cavity of the vane pump, the temperature rise of the oil in the sealed cavity of the oil discharge region consists of three 
parts: the friction between the tip of the vane and the inner surface of the stator ring, friction between the vane and rotor slot, and friction of the valve pair.

\subsubsection{The Frictional Heat Generation of the Vane}

The force status of the vanes in the oil suction and oil discharge regions is different due to the special structure of the stator curve of the double-acting vane pump. Figure 5 shows the analysis of the force status of the vanes in the oil discharge region.

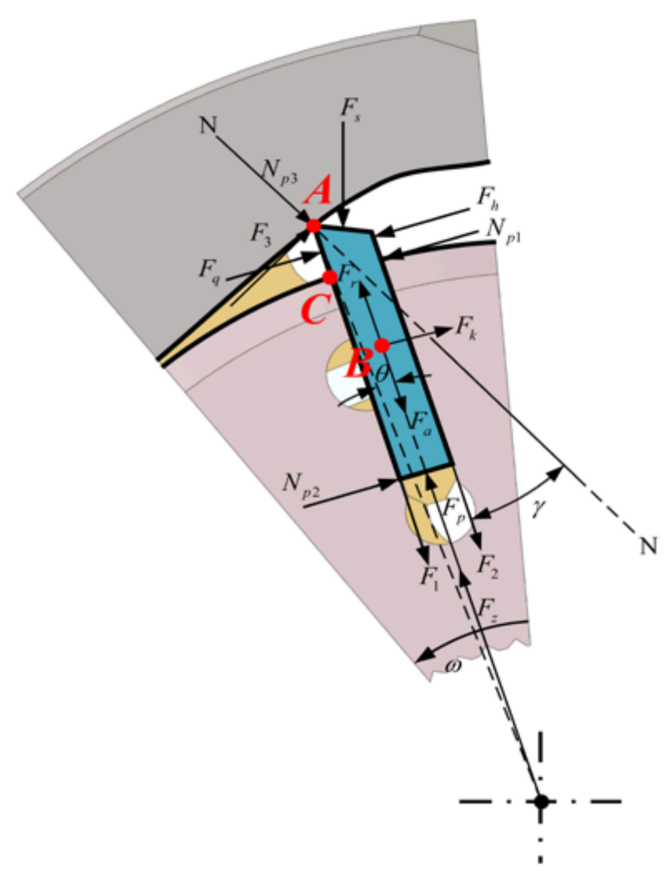

Figure 5. Force analysis of vanes in the oil discharge region.

As shown in Figure 5, the sum of the forces along the vane direction and the perpendicular vane direction is zero. The moment balance equation of each force to point $A$ is zero, and the equation is obtained as follows:

$$
\begin{gathered}
N_{p 2} h-N_{p 1} A C+F_{r} \frac{s}{2}-F_{a} \frac{s}{2}+F_{k} d-F_{s} L_{s}+N_{p 2} f s+F_{p} \frac{s}{2}+F_{z} \frac{s}{2}-F_{h} L_{h}+F_{q} L_{q}=0 \\
N_{p 3} \cos \gamma-N_{p 3} f \sin \gamma+F_{S} \sin \theta-N_{p 1} f-N_{p 2} f+F_{a}-F_{r}-F_{p}-F_{z}=0 \\
N_{p 1}-N_{p 2}-N_{p 3} \sin \gamma-N_{p 3} f \cos \gamma+F_{s} \cos \theta-F_{k}+F_{h}-F_{q}=0
\end{gathered}
$$

where $N_{p 1}, N_{p 2}$ is the contact reaction force of the rotor groove on the vane; $N_{p 3}$ is the contact reaction force of the stator ring on the tip of the vane; $F_{s}$ is the hydraulic force on the tip of the vane caused by oil pressure; $F_{q}$ is the hydraulic force on the front side of the vane caused by oil pressure; $F_{h}$ is the hydraulic force on the back side of the vane caused by oil pressure; $F_{z}$ is the hydraulic force in the middle of the vane; $L_{s}, L_{q}, L_{h}$ are the force arms of the hydraulic force $F_{s}, F_{q}$, and $F_{h} ; \theta$ is the backward angle of vane.

Additionally, due to the short movement period of the vane in the oil discharge region, the heat generation analysis is conducted according to its dynamic analysis. The friction heat generation equation between the vane and the stator and the friction heat generation equation between the vane and the rotor slot are obtained as follows, respectively:

$$
\begin{gathered}
Q_{4}=\int_{0}^{\frac{3 \pi}{10 \omega}} z N_{p 3} f \omega \rho d t \\
Q_{5}=\int_{0}^{\frac{3 \pi}{10 \omega}} z\left(N_{p 1}+N_{p 2}\right) f v d t
\end{gathered}
$$


where $Q_{4}$ is the frictional heat generation between the vane and the inner surface of the stator ring; $Q_{5}$ is the frictional heat generation between the vane and rotor groove.

\subsubsection{The Temperature Rise Caused by the Oil Film in the Oil Discharge Region}

As shown in Figure 6, in the oil discharge region, the upper and lower parts of the $\mathrm{B}$ region correspond to the high-pressure region of the oil discharge port and the highpressure region where the pressure equalizes the groove of the vane middle cavity is located. Thus, there is no pressure difference on both sides of the B region. Therefore, the temperature rise caused by the oil film of the port pair in the oil discharge region only depends on the shear flow.

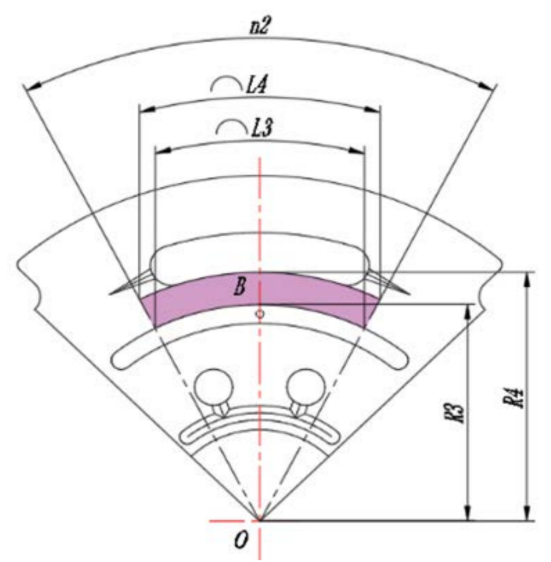

Figure 6. Mathematical calculation model for region B.

The frictional power loss of the shear flow is given by

$$
E_{1}=\frac{3 \pi b^{\prime} \mu\left(R_{3}+R_{4}\right) U^{2}}{20 h^{\prime}}
$$

The heat power increased by the oil film is given by

$$
E_{2}=\frac{\rho_{1} c_{1} h^{\prime} b^{\prime} U}{2} \Delta T
$$

Suppose the heat increase in the oil in the sealed cavity caused by the distribution pairs on both sides of the sealed cavity is $Q_{6}$. According to the law of energy conservation, the thermal power $P_{2}$ on one side is calculated as follows:

$$
P_{2}=E_{1}+E_{2}
$$

The temperature rise is calculated as

$$
\Delta T=\frac{3 \pi \mu\left(R_{3}+R_{4}\right)}{10 h^{\prime 2} c_{1} \rho_{1}} U
$$

\subsection{Heat Dissipation Analysis of Oil in the Sealed Cavity}

Part of the heat generated by the friction between the vane and the inner surface of the stator ring and rotor groove remains in the oil. The other part is dissipated by the conduction of the pump shell, the heat convection between the pump shell and the air, and the radiation of the pump shell. Therefore, it is necessary to analyze the heat conductivity of the pump shell, the convection heat dissipation of the pump shell and the air, and the radiation heat dissipation of the pump shell. 


\subsubsection{Conduction Heat Dissipation of the Shell}

In the heat transfer process, the shell is difficult to analyze with traditional heat transfer theory due to its irregular shape. Therefore, if the thermal resistance is used to analyze the heat conduction of the shell, the heat conduction equation of the shell is obtained as

$$
Q_{7}=\frac{T_{1}-T_{2}}{R_{d}}
$$

Where $Q_{7}$ is the heat lost by heat conduction of the pump shell; $T_{1}$ is the temperature of the inner wall of the pump shell; $T_{2}$ is the temperature of the outer wall of the pump shell; $R_{d}$ is the thermal conductivity of pump shell.

\subsubsection{Convection Heat Dissipation between the Shell and the Ambient}

The pump is used for experiments in the laboratory, and indoor air flows at a certain speed. Then, the Reynolds number of the air passing over the pump shell is given by

$$
\operatorname{Re}=\frac{\rho_{2} u_{1} d_{1}}{\mu_{1}}
$$

where $u_{1}$ is the wind speed; $\mu_{1}$ is the dynamic viscosity of air; $\rho_{2}$ is the density of air; $d_{1}$ is the outer diameter of the pump shell.

If the range of Reynolds number is $0<R e<1000$, the laminar flow relation is selected as

$$
\begin{gathered}
N u=0.44 R e^{1 / 2} \\
h_{1}=\frac{N u \lambda_{2}}{d_{1}}
\end{gathered}
$$

where $N u$ is the Nusselt number; $h_{1}$ is convection heat transfer coefficient of air; $\lambda_{2}$ is the thermal conductivity of air.

Therefore, the convective heat exchange between the pump shell and air is given by

$$
Q_{8}=h_{1} A_{1}\left(T_{2}-T_{0}\right)
$$

where $Q_{8}$ is the convection heat dissipation of pump shell; $A_{1}$ is the external surface area of the pump shell.

\subsubsection{Heat Dissipation of Shell by Radiation}

The vane pump continuously emits radiant energy into the room, also continuously absorbs the radiant energy in the room and converts it into heat energy again. Since the temperature of the pump is higher than that of the room, the heat will be transmitted from the pump to other low-temperature objects in the laboratory in the form of electromagnetic wave. The equation of shell dissipation heat by radiation can be expressed as:

$$
Q_{9}=\varepsilon \sigma A_{1}\left(T_{2}^{4}-T_{0}^{4}\right)
$$

where $Q_{9}$ is the heat dissipation of pump shell by radiation; $\varepsilon$ is the emissivity of the object; $\sigma$ is the blackbody radiation constant.

\subsection{Thermodynamic Model of Heat in the Sealed Cavity}

According to the first law of thermodynamics, different forms of energy are conserved during the transfer and conversion process. The established oil enters the sealed cavity from the oil suction region and is discharged to the oil discharge region. The oil thermodynamic model equation of the sealed cavity can be expressed as

$$
\Delta Q=\left(Q_{1}+Q_{2}+Q_{3}+Q_{4}+Q_{5}+Q_{6}\right)-\left(Q_{7}+Q_{8}+Q_{9}\right)
$$


where $\Delta Q$ is the increase in internal energy of oil and other parts in the pump.

\section{Thermodynamic Simulation and Analysis}

The oil temperature rise in the sealed cavity of the vane pump is calculated and analyzed using the above model. Table 1 presents the main structural parameters of the vane pump.

Table 1. Structural and simulation parameters.

\begin{tabular}{lll}
\hline \multicolumn{1}{c}{ Parameters } & Value \\
\hline Rotating speed $(\mathrm{r} / \mathrm{min})$ & 1500 & \\
Displacement $(\mathrm{mL} / \mathrm{r})$ & 67.5 \\
Rated pressure $(\mathrm{MPa})$ & 21 & \\
Vanes number & 10 \\
Friction coefficient & 0.13 \\
Vane thickness $(\mathrm{m})$ & 0.0031 \\
Vane mass $(\mathrm{kg})$ & 0.012 \\
Oil film thickness $(\mu \mathrm{m})$ & 20 \\
Pressure angle $\left({ }^{\circ}\right)$ & 7 \\
Large arc radius $(\mathrm{m})$ & 0.0397 \\
Small arc radius $(\mathrm{m})$ & 0.0353 \\
\hline
\end{tabular}

Since the oil suction and oil discharge regions of the composite vane pump have different mechanisms of oil temperature rise in the sealed cavity, it is necessary to simulate and analyze the two situations separately.

\subsection{Analysis of Heat Generation in the Oil Suction Region}

Figure 7 shows the oil temperature rise in the sealed cavity caused by the friction and heat generated by the vanes in the oil suction region. As shown in the figure, the temperature rise of the oil in the sealed cavity caused by the frictional heat generation of the two pairs of friction pairs is linear and positively correlated with time under the working condition of the outlet pressure of the vane pump of $3 \mathrm{MPa}$.

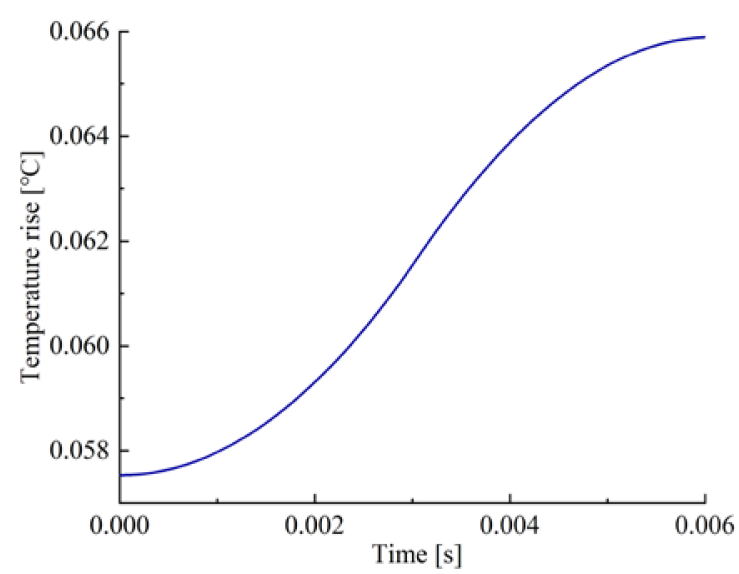

Figure 7. Variations in the temperature rise of the oil in the sealed cavity of the oil suction region.

Figure 8 shows the change in the temperature rise of the oil film in the valve port of the vane pump with the pressure. As shown in the figure, the temperature rise of the oil film first decreases and then increases with the pressure. The main cause of temperature rise is the shear flow for low pressure, and the pressure difference flow does not generate heat. However, as the pressure increases, the heat generated by the differential pressure flow becomes an essential factor affecting the temperature rise of the oil. Therefore, the temperature rise increases. 


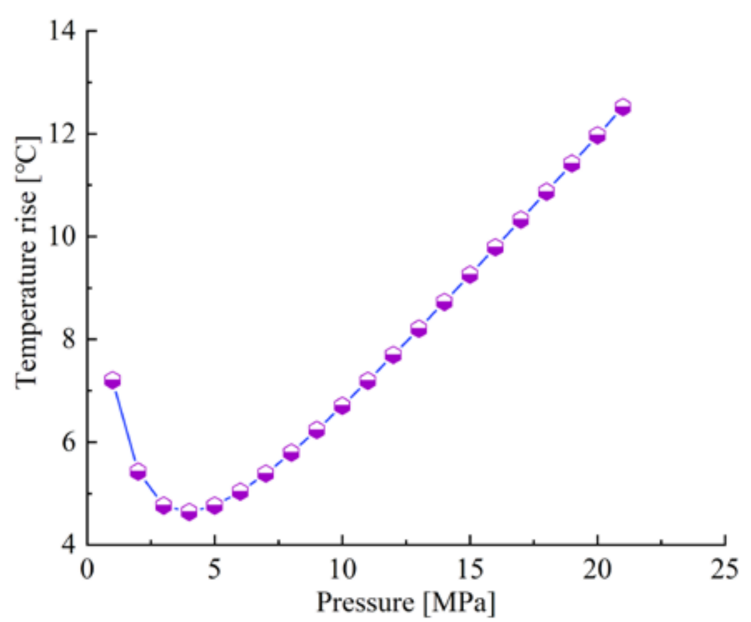

Figure 8. Variations in the temperature rise of the oil film of the valve pair.

\subsection{Analysis of Heat Generation in the Oil Discharge Region}

Figure 9 shows the change in the temperature rise of the oil due to vane friction in the oil discharge region. As shown in the figure, when the outlet pressure of the vane pump is $3 \mathrm{MPa}$, the two pairs of friction pairs in the oil discharge region cause the temperature rise of the oil in the sealed cavity to change in a linear relationship with time.

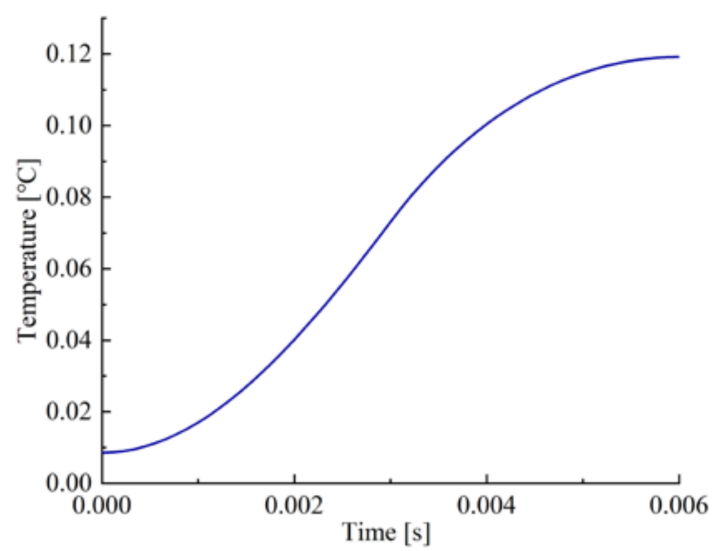

Figure 9. Variations in the temperature rise of the oil in the sealed cavity of the oil discharge region.

Figure 10 shows the change in the temperature rise of the oil film of the valve pair with the slip speed. As shown in the figure that, the temperature rise of the oil of the valve pair has a linear relationship with the relative sliding speed. The figure shows the changing trend of temperature rise of the oil film under the action of pure shear force. It is the relative sliding speed that affects the change in shear force.

\subsection{Oil Temperature Rise in Sealed Cavity of Vane Pump}

Figure 11 shows the change curve of the temperature rise of the oil in the sealed cavity with time under different outlet pressures.

As shown in Figure 11, the temperature of the oil rises sharply when the pump first starts to work. After some time, the temperature starts to level off and finally stabilizes. Simultaneously, the temperature of the oil increases faster as the outlet pressure increases.

In the research process of this paper, the influence of temperature on the oil viscosity is ignored, and the viscosity of the oil at a certain temperature is taken as a fixed value. Additionally, the pump has good sealing performance. The influences of leakage loss on the oil temperature and heat production are not considered. They are produced by friction because friction is the main factor that generates heat. The main consideration for heat 
dissipation is the heat conduction of the shell itself, the convection heat exchange between the shell and environment, and the radiative heat dissipation of the shell.

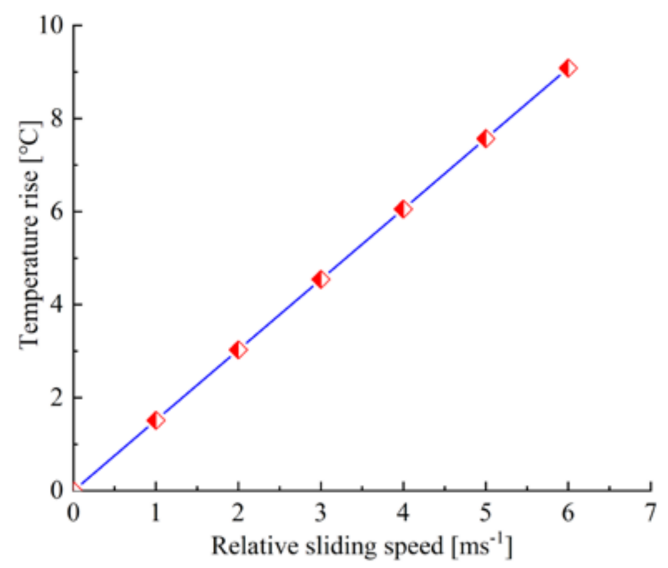

Figure 10. Variation in the temperature rise of the oil film with a sliding speed in the distribution pair.

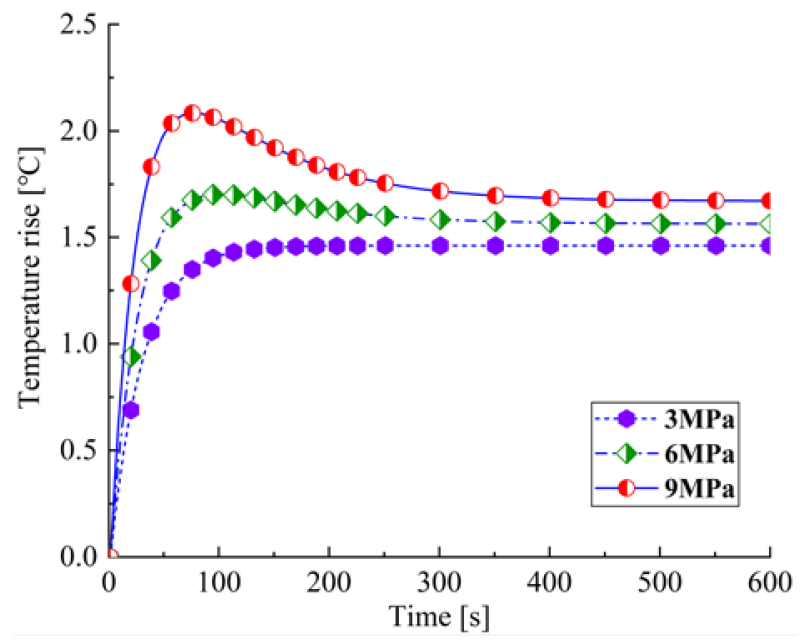

Figure 11. Changes in oil temperature rise caused by heat generation and heat dissipation.

\subsection{Comparison of Oil Temperature Rise Caused by Various Heat-Generating Sources in a Sealed Cavity}

There are several heat-generating sources in the oil suction and oil discharge sealed cavity of the composite vane pump, and the proportions of each heat-generating source are different. The force state of the vanes in the oil suction and oil discharge regions is different. Therefore, it is necessary to analyze the proportion of each heat source in the total heat production in the oil suction and oil discharge regions to provide a reference for further optimization of the vane pump.

\subsubsection{Comparison of Oil Temperature Rise Caused by Various Heat Sources in the Oil} Suction Region

Figure 12 shows the temperature rise caused by the heat sources in the three parts of the oil suction region under different outlet pressures.

As shown in the figure, the temperature rise caused by each heat source in the oil suction region under different pressure conditions is quite different. Additionally, the temperature rise caused by the friction heat between the vane and stator is the largest.

The analysis shows that although the temperature rise caused by the orthogonality of the differential pressure flow and the shear flow has a greater impact on the temperature rise of the sealed cavity oil, the temperature rise caused by the orthogonality accounts for the total oil temperature as the pressure increases. The proportion of the temperature rise 
of the oil gradually decreases, and the proportion of friction heat between the vanes and the stator ring gradually increases as pressure increases.

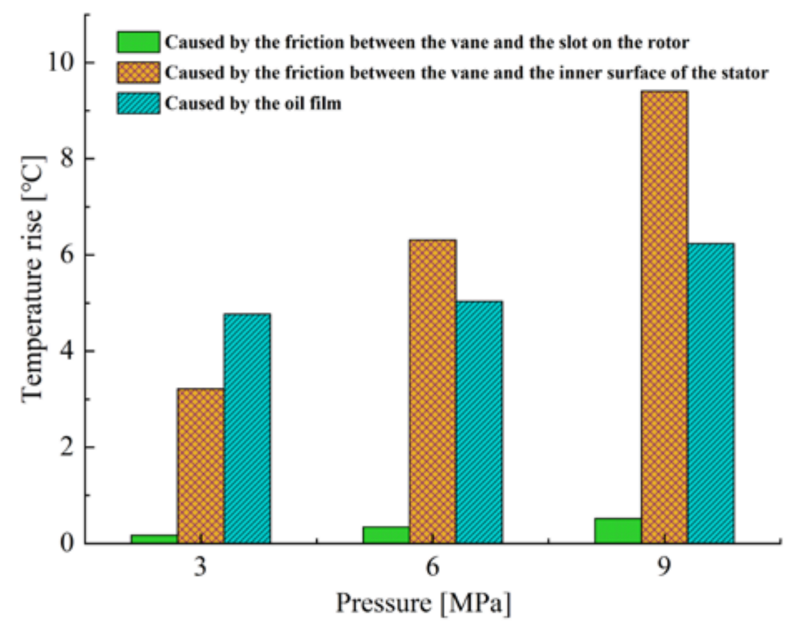

Figure 12. Comparison of the temperature rise of the oil caused by the heat sources in the three parts of the oil suction region.

Therefore, under the condition of only changing the pressure, at low pressure, the heat generated by the orthogonality of the differential pressure flow to the shear flow is the main heat source. However, at high pressure, the main heat source is the frictional heat between the vane and the stator ring.

\subsubsection{Comparison of Oil Temperature Rise Caused by Various Heat Sources in the Oil} Discharge Region

Figure 13 shows the temperature rise caused by the heat sources in the three parts of the oil discharge region under different working pressures.

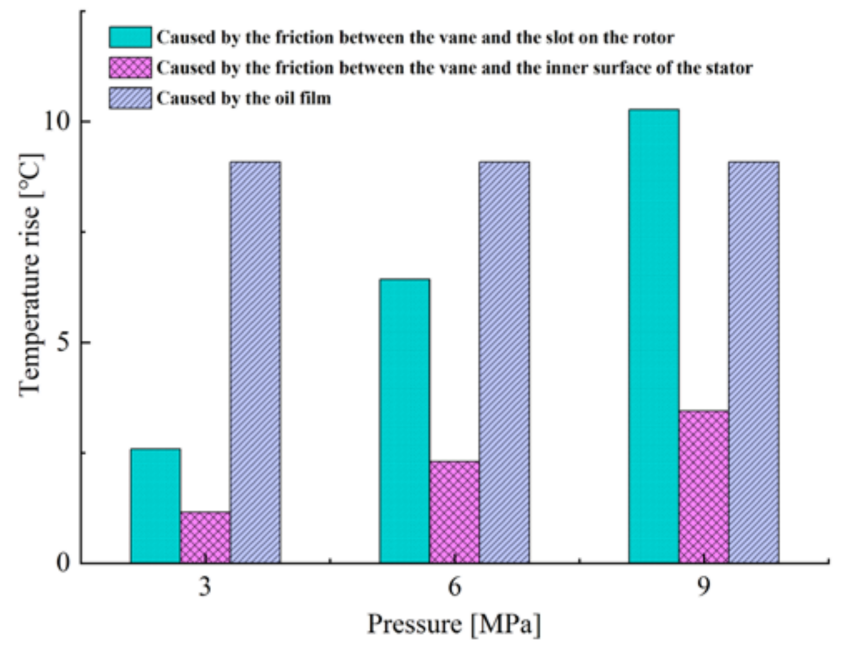

Figure 13. Comparison of temperature rise caused by frictional heat generation in the three parts of the oil discharge region.

As shown in the figure, the magnitude of the temperature rise caused by the heat source in the oil discharge region under different pressure conditions is also different.

The comparative analysis shows that although the pure shear flow has a relatively large influence on the temperature rise of the oil in the sealed cavity, the proportion of the temperature rise caused by the pure shear flow gradually decreases as the pressure increases and the difference between the vane and the rotor groove. The proportion of heat produced by inter friction increases gradually. 
Therefore, at low pressure, the heat generated by pure shear flow is the main heat source. In contrast, at high pressure, the main heat source is the frictional heat between the vane and rotor slot.

4.4.3. Comparison of the Temperature Rise of the Heat Dissipation of Each Heat Dissipation Route in the Sealed Cavity

Part of the heat generated in the sealed cavity of the vane pump is taken away by the oil; part becomes the internal energy of various parts. Part is dissipated by the heat conduction of the pump shell, the convection between the pump shell and air, and the radiation of the pump shell.

Figure 14 shows the temperature rise of the heat taken away using the three heat dissipation methods under different pressure conditions. This can also be understood as a negative temperature rise.

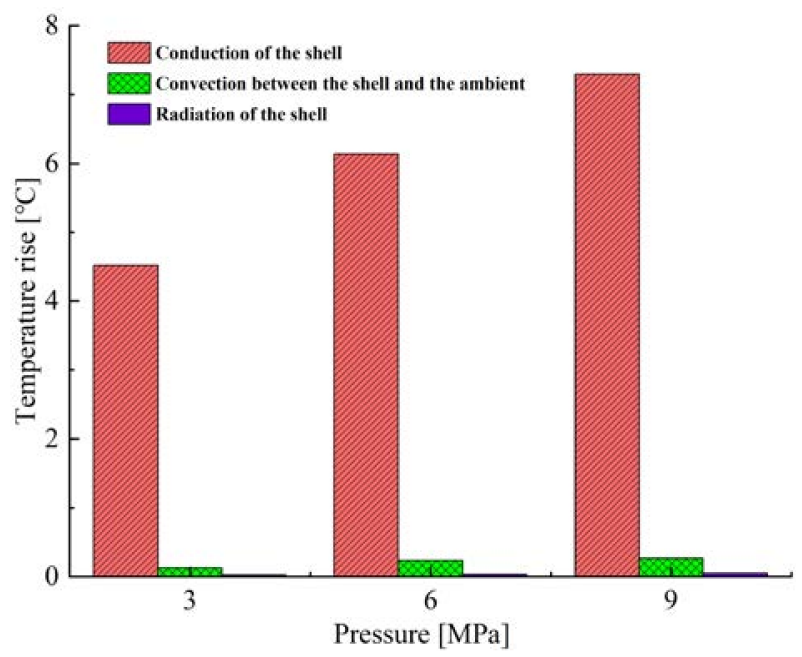

Figure 14. Comparison of the temperature rise of the three heat dissipation methods.

As shown in the figure, the double-acting vane pump has multiple heat dissipation channels. When the rotation speed is constant, the heat dissipation of each heat dissipation path under different outlet pressures is different. The heat conduction of the shell has the largest heat dissipation, followed by the convection heat exchange between the shell and air. The smallest is the radiant heat dissipation of the pump shell. Because the temperature difference between the ambient temperature and the surface of the pump shell is relatively small and the effective heat dissipation region of the shell is relatively small, the radiation heat dissipation of the pump shell is the smallest. The temperature rise between each heat dissipation path increases as the outlet pressure of the vane pump increases. As the pressure increases, the temperature rise of each heat dissipation path increases, but the proportion of each heat dissipation path does not change. Therefore, the main heat dissipation path is the heat conduction of the shell.

\section{Test of Oil Temperature Rise and Analysis of Result}

Since there are many factors affecting the temperature rise of the oil in the sealed cavity, a purely theoretical analysis cannot fully reflect the true situation of the temperature rise of the oil in the sealed cavity. Therefore, it is necessary to design a temperature test to analyze the temperature rise of the oil in the sealed cavity.

\subsection{Design of Oil Temperature Test System in the Sealed Cavity}

To accurately reflect the change in the oil temperature in the sealed cavity under different working conditions, the author built a set of test benches that can measure the change in the oil temperature in real time. Use the throttle valve to load and change the 
output pressure of the vane pump to ensure a certain speed [25]. Figure 15 shows the working principle diagram.

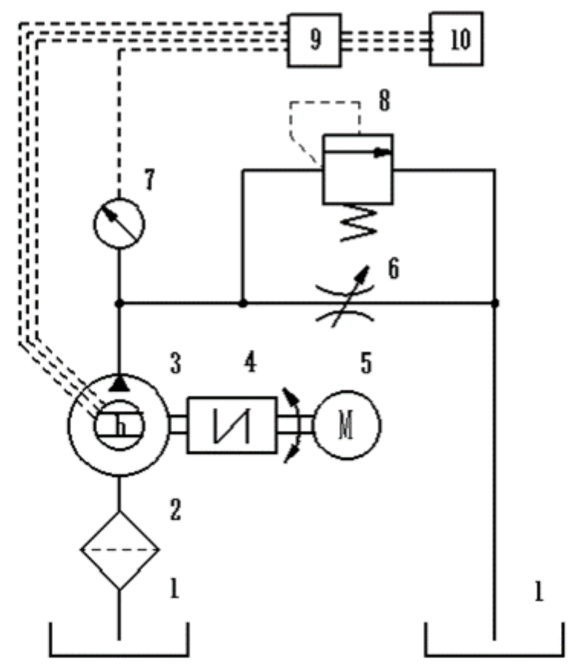

Figure 15. Schematic of the test system. 1-oil tank 2-filter 3-vane pump 4-coupling 5-motor 6-throttle valve 7-pressure gauge 8-overflow valve 9-digital temperature recorder 10-computer.

\subsection{Selection of the Temperature Collection Point}

Considering the working principle of the intra-vane type pump and the structure of the oil suction and discharge cavity, six collection points are chosen to collect the temperature to analyze the change in oil temperature in the oil suction and oil discharge cavity. The positions are the outer surface of the stator ring corresponding to the oil suction port, oil discharge port, oil suction region, and oil discharge region, and the outer surface of the shell corresponding to the oil suction and oil discharge regions [26].

The temperature collection points of the oil suction port and oil discharge port are used to test the change of oil temperature in the sealed cavity. The other four temperature collection points are used to test the temperature difference inside and outside the pump shell in the oil suction area and oil discharge area respectively. Because the temperature collection point on the inner wall of the shell is not conducive to the installation of the sensor and the heat conduction between the inner wall of the shell and the outer surface of the stator ring can be ignored, the temperature collection points are determined as the outer surface of the stator ring corresponding to the suction and discharge region. The other two collection points need to measure the temperature of the other end of the shell heat conduction, i.e., the outer wall of the shell corresponding to the oil suction and discharge regions. The platinum resistance temperature sensor was selected in the test, and the test site is shown in Figure 16.

\subsection{Analysis of Test Results}

The Temperature Change of Heat Dissipation

When the vane pump works under different working pressures, the corresponding heat dissipation is different. Figure 17 shows that analyzing the test data collected under different working pressures, the oil temperature rise curve is converted by the heat taken away using the three heat dissipation methods. This can also be understood as a negative temperature rise.

As shown in the figure, when the high-pressure vane pump starts to work, the heat dissipation increases sharply. However, it becomes flat after a period of operation. This is because the ambient temperature inside the pump is relatively low at the beginning; thus, the heat dissipation of the oil will increase sharply. As the pressure increases, the longer it takes for the heat dissipation to stabilize. Thus, ensuring that other working conditions remain unchanged. When the pressure is $3 \mathrm{MPa}$, the heat dissipation will stabilize in about 
$2 \mathrm{~min}$. In contrast, the heat dissipation will stabilize in about 3 min when the pressure is 9 $\mathrm{MPa}$.

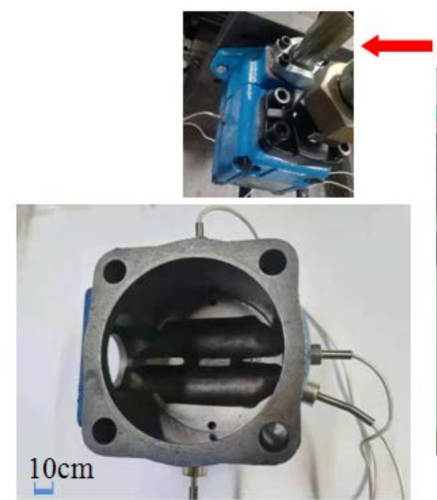

(a)

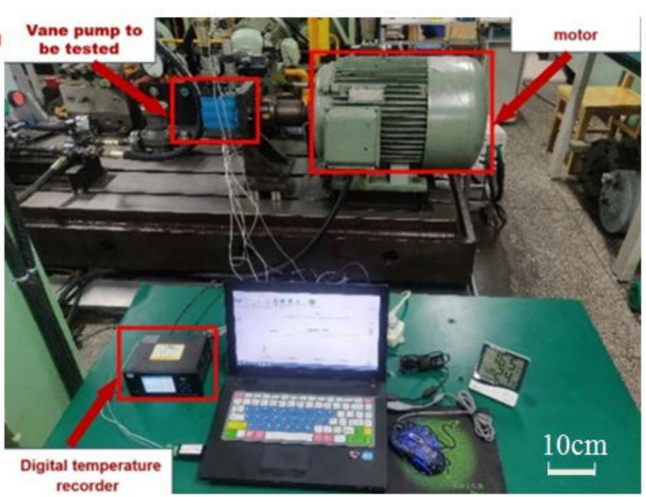

(b)

Figure 16. The pump shell and Test site diagram. (a) The pump shell with temperature sensors; (b) Test site diagram.

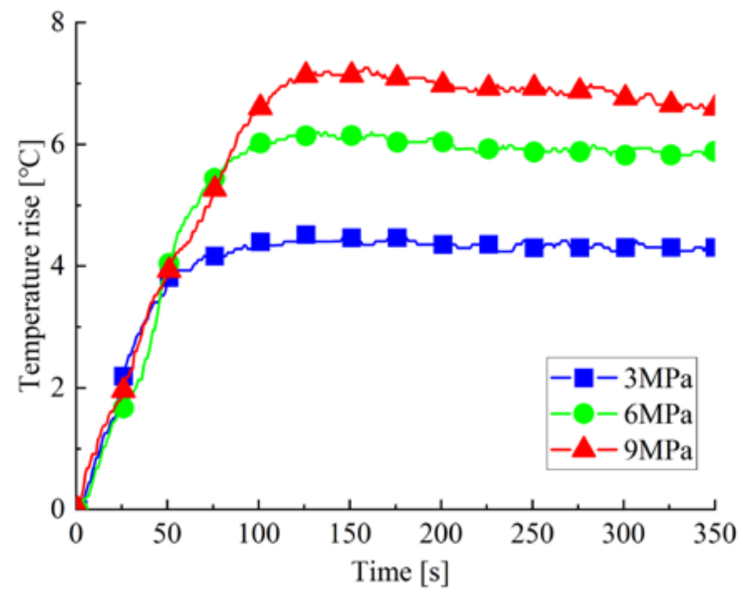

Figure 17. Measured data of the change in heat dissipation of oil in a sealed cavity under different pressures.

\section{Discussion}

According to the temperature change and heat transfer mode of the oil in the oil suction and oil discharge cavity of the intra-vane pump, a thermodynamic model of each transfer path is established. This model can effectively predict the temperature change in oil in oil suction and oil discharge region. The validity of the model can be verified by comparing the theoretical and experimental data.

Figure 18 shows the curve of the temperature rise of the oil at the oil discharge port relative to the oil suction port collected in the experiment with time.

As shown in Figure 18, when the vane pump starts to operate and adjusts the outlet pressure to the set value, the oil temperature rises sharply to the peak and then decreases slowly and stabilizes. This is because the first adjustment of the throttle valve and the overflow valve changed the outlet flow of the pump; thereby, changing the outlet pressure of the vane pump. When the pressure increases sharply, the temperature rises rapidly, reaching the peak value. With the operation of the pump and the increase in the oil temperature at the suction port, the pressure gradually stabilizes, and the temperature difference stabilizes. When the pressure is $3 \mathrm{MPa}$, the maximum temperature rise can reach $2.3^{\circ} \mathrm{C}$. In contrast, the maximum temperature rise can reach $5{ }^{\circ} \mathrm{C}$ when the pressure is $9 \mathrm{MPa}$. 
Based on the analysis of the temperature data collected from the thermodynamic model of the sealed cavity and the test, the relationship between the theory and test data under the condition of the outlet pressure of $6 \mathrm{MPa}$ and the rotating speed of $1500 \mathrm{r} / \mathrm{min}$ is compared to verify the validity of the model. Figure 19 shows the theoretical and experimental curves of temperature rise over time.

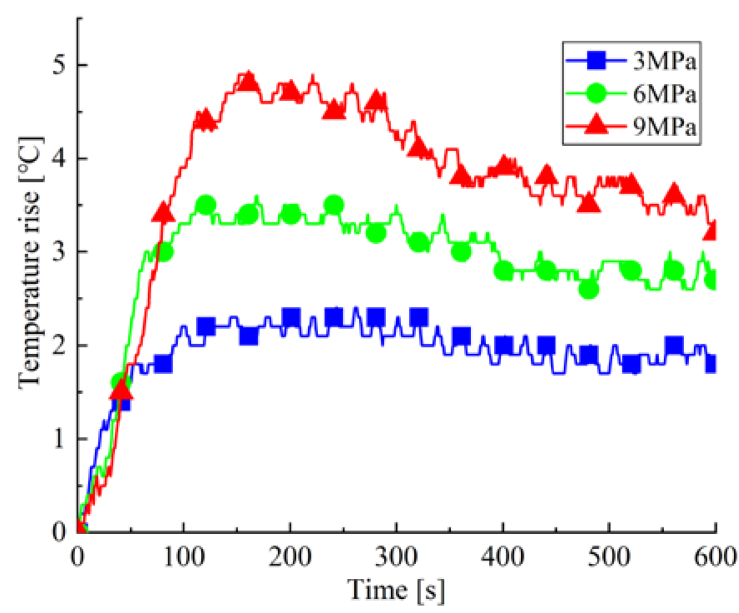

Figure 18. Temperature rise of the oil discharge port relative to the oil suction port under different pressures.

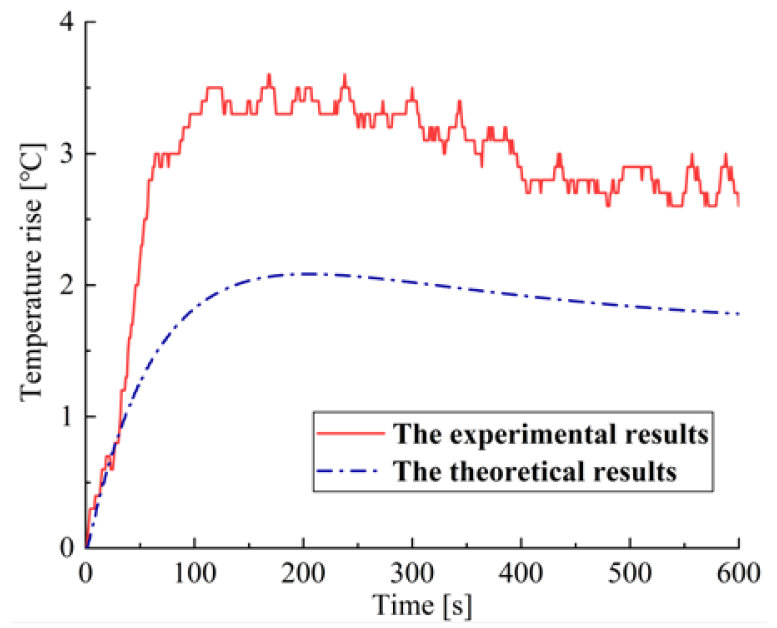

Figure 19. Comparison of the theoretical calculation and test data.

As shown in Figure 19, the changing trend of the experiment and theory is the same. Additionally, the temperature rises sharply when the pump starts to work, and the temperature tends to be flat after working for some time. The temperature rise of the curve obtained from the test analysis tends to rise again after working for some time. This is because, theoretically, the temperature of the oil sucked by the oil suction port should be constant; however, the oil temperature of the oil suction port collected in the test gradually increases. Therefore, the collected heat dissipation temperature rise will increase, but the ambient temperature remains constant. Thus, the temperature rise will increase again after a period of work.

The temperature rise of the test analysis reached a plateau in about $7 \mathrm{~min}$. In contrast, the theoretical temperature rise reached a plateau in about $5 \mathrm{~min}$. This is because the time consumed by the loading pressure is not considered. The theoretical calculation is calculated using a fixed pressure, and the test is from non-pressurized to the required pressure; thus, there will be a time delay.

There is a significant deviation between the theoretical calculation and test results. The analysis shows that because the theoretical calculation only considers the influence of oil 
suction and oil discharge regions on oil temperature, it does not consider heat production in the two large arcs and two small arcs. The oil viscosity affects the temperature and the installation position of the temperature collection point. Thus, the temperature rise of the test analysis is higher than the theoretical calculation. When the outlet pressure is $6 \mathrm{MPa}$, the maximum temperature rise of the theoretical calculation is $2^{\circ} \mathrm{C}$. Meanwhile, the maximum temperature rise of the experimental analysis is $3.5^{\circ} \mathrm{C}$.

In addition, the temperature rise curve of the heat dissipation conversion of the closed cavity calculated theoretically and the heat dissipation conversion temperature rise curve tested experimentally are compared, that is, Figures 14 and 17. It can be seen that the heat dissipation temperature rise of heat conduction route under each working pressure in Figure 14 is close to the heat dissipation temperature rise value of the same working pressure in Figure 17. Under the three working pressures, the theoretical value is greater than the experimental value, and the maximum error is $0.5^{\circ} \mathrm{C}$.

\section{Conclusions}

This paper takes the 25VQ21A double-acting vane pump as the research object. It analyzes the heat generation and heat dissipation sources of oil in oil suction and discharge airtight cavity during its working process. Consequently, their heat generation model is established theoretically and experimentally. The following conclusions are obtained from the combined method.

(1) The sealed cavity is located in the oil suction region. When the working pressure is low, the heat generated by the orthogonal pressure difference flow and the shear flow of the distribution pair contributes greatly to the temperature rise of the oil. In contrast, when the working pressure is high, the friction between the vanes and the inner surface of the stator is the main source of heat production, and the temperature rise of the oil in the sealed cavity caused by the three heat production sources increases as the working pressure increases.

(2) The sealed cavity is located in the oil discharge region. When the working pressure is low, the heat generated by the valve plate pair's shear flow contributes greatly to the oil temperature rise. In contrast, as the working pressure increases, the frictional heat generated by the vane and the rotor groove is the main heat source. As the working pressure increases, the heat generated by the shear flow causes the oil temperature rise to remain constant, and the other two heat generation sources cause the oil temperature to rise to increase gradually.

(3) Among the three heat dissipation sources of oil in the sealed cavity of the vane pump, the heat conduction heat dissipation of the shell is the largest, and the heat radiation heat dissipation of the shell is the smallest. However, as the working pressure increases, only the heat conduction and heat dissipation of the shell increase, and the other two have smaller changes.

(4) The theoretical calculation of the relationship between the temperature rise of the oil in the sealed cavity and the changing trend of the test results is consistent with the changing trend of the test results. However, there is a significant deviation in the value, and the temperature rise of the test is higher than that of the theoretical calculation. The analysis shows that the main reason is that the theoretical calculation does not consider the influence of heat generation and oil viscosity on the temperature in the two large arcs and two small arcs.

Author Contributions: Conceptualization, supervision, project administration, funding acquisition, S.L.; writing-methodology, original draft preparation, software, P.Y.; data curation, validation, R.Z.; formal analysis, writing-review and editing, T.L.; investigation, resources, Z.Z. All authors have read and agreed to the published version of the manuscript.

Funding: This work was supported by the National Natural Science Foundation of China (Grant No. 52165006) and Industrial Support and Guidance Project of Colleges and Universities in Gansu 
Province (Grant No. 2019C-13). The authors gratefully acknowledge them for financial support of this work.

Institutional Review Board Statement: Not applicable.

Informed Consent Statement: Not applicable.

Data Availability Statement: Not applicable.

Conflicts of Interest: The authors declare no conflict of interest.

\section{References}

1. Ji, H. Hydraulic and Pneumatic Transmission and Control; Huazhong University of Science \& Technology Press: Wuhan, China, 2009. (In Chinese)

2. Bai, J.J.; Xu, M.M. Research status and development trend of vane pump. Appl. Mech. Mater. 2014, 556-562, 1143-1146. [CrossRef]

3. Li, K.; Lu, X.S. Vane Type Hydraulic Pumps and Motors; China Machine Press: Beijing, China, 1993. (In Chinese)

4. Wang, R.J. Calculation of temperature-increase for the friction couple of connecting rod slipping shoe and swash-plate in the axial plunger motor. Lubr. Eng. 1995, 20, 50-56. (In Chinese)

5. Wang, H.Y. Design of Rotary Motor and Study of Piston Friction Pair. Master's Thesis, Southwest Jiaotong University, Chengdu, China, 2009. (In Chinese).

6. Ma, J.; Li, Y.B.; Pan, Y. Performance analysis and mathematical modeling of temperature field on piston/cylinder assembly J. Cent. South Univ. (Sci. Technol.) 2018, 49, 330-338. (In Chinese)

7. Gao, D.R.; Zhang, Z.Y.; Sun, Y.N.; Xu, S.H.; Liu, J.C.; Zhang, Y. Numerical simulation and analysis of temperature and flow field of high-speed axial piston motor pump. J. Eng. 2019, 13, 127-131. [CrossRef]

8. Zhou, Y.; Ci, Y. Temperature rise of journal bearing of the high-speed circular arc gear pump. Proc. Inst. Mech. Eng. Part C J. Mech. Eng. Sci. 2020, 234, 1492-1499. [CrossRef]

9. Li, C.G.; Jiao, Z.X. Thermal hydraulic modeling and simulation of piston pump. Chin. J. Aeronaut. 2006, 19, 354-358. (In Chinese) [CrossRef]

10. Han, M.; Cao, K.Q.; Hu, L.M.; Li, Y.L. Thermal model and simulation on hydraulic piston pump based on AMESim. Hydromechatronics Eng. 2012, 40, 136-138. (In Chinese)

11. Tang, Z.Y. Thermodynamic Study of Water-oil Separation Valve Distribution Water Pressure Piston Pump. Master's Thesis, Huazhong University of Science \& Technology, Wuhan, China, 2015. (In Chinese).

12. Tang, H.S.; Li, J.; Yin, Y.B. Thermal clearance and influencing factors analysis of slipper pair in axial piston pump. J. Tongji Univ. (Soc. Sci. Sect.) 2015, 43, 1743-1749, 1764. (In Chinese)

13. Sun, H.G.; Li, J.; Ye, B. Analysis of thermal model and heat generation of aero fuel piston pump. Comput. Simul. 2016, 33, 125-129. (In Chinese)

14. Li, D.L.; Li, G.Q.; Han, J.H.; Liu, Y.S.; Wu, D.F. Thermodynamic characteristics research of a water lubricating axial piston pump. Proc. Inst. Mech. Eng. Part C J. Mech. Eng. Sci. 2020, 234, 3873-3889. [CrossRef]

15. Ivantysynova, M.; Huang, C. Thermal Analysis in Axial Piston Machines Using CASPAR. Proceedings of 6th International Conference on Fluid Power Transmission and Control, Hangzhou, China, 12-14 April 2005.

16. Huang, B.S. Innovative design and simulation for a novel vane pump. Adv. Mater. Res. 2011, 328-330, 354-359. [CrossRef]

17. Li, S.N.; Chen, L.; Zhang, L.; Zhao, R.; Hu, Z.M. Temperature rise characteristics of oil film in flow distribution pair of high pressure intra-vane type pump. Trans. Chin. Soc. Agric. Eng. (Trans. CSAE) 2019, 35, 52-59. (In Chinese)

18. Li, S.N.; Wei, L.J.; Ji, H.; Wang, Z.R.; Na, Y.Q. Effect of improved stator curve on characteristic of high-pressure intra-vane type pump. Trans. Chin. Soc. Agric. Mach. 2012, 43, 119-223. (In Chinese)

19. Zhan, G.T.; Yin, Y.G. Pressure variation in sealed cavity and force analysis on vanes in variable displacement vane pumps. Appl. Math. Mech. 2014, 35, 401-411. (In Chinese)

20. Yang, S.M.; Tao, W.Q. Heat Transfer, 4th ed.Higher Education Press: Beijing, China, 2011. (In Chinese)

21. Na, Y.Q.; Li, S.N.; Wang, Z.R.; Na, C.L. Kinetic analysis of vane in composite vane pump. J. Lanzhou Univ. Technol. 2004, 30, 61-63. (In Chinese)

22. Fiebig, W.; Cependa, P.; Kuczwara, H.; Wang, F. Analysis of vane loads and motion in a hydraulic double vane pump with integrated electrical drive. Arch. Civ. Mech. Eng. 2021, 21, 112. [CrossRef]

23. Cho, I.S. Behavioral characteristics of the vane of a hydraulic vane pump for power steering systems. J. Mech. Sci. Technol. 2015, 29, 4483-4489. (In Chinese) [CrossRef]

24. Li, S.N.; Liu, Y.Y.; Lin, K.; Chen, L. Analysis and calculation of internal leakage in double-acting pump with composite vanes. Mach. Tool Hydraul. 2019, 48, 134-137. (In Chinese)

25. Ji, H.; Li, Z.F.; Wang, Z.R.; Wang, J.S.; Lan, B.J. Performance test of the proto type of electric motor pump. Trans. Chin. Soc. Agric. Mach. 2010, 41, 48-51, 56. (In Chinese)

26. Wang, K.H.; Li, Y.; Wang, B.Z. The latest developing status of the technology of temperature measurement and the unique and practical measuring technologies. Process Autom. Instrum. 2001, 22, 3-9. (In Chinese) 